Experimental analysis of a high temperature

$$
\begin{aligned}
& \text { water heat pipe for thermal storage } \\
& \text { applications }
\end{aligned}
$$

Thomas C. Werner, Yuying Yan, David Mullen,

Elvedin Halimic

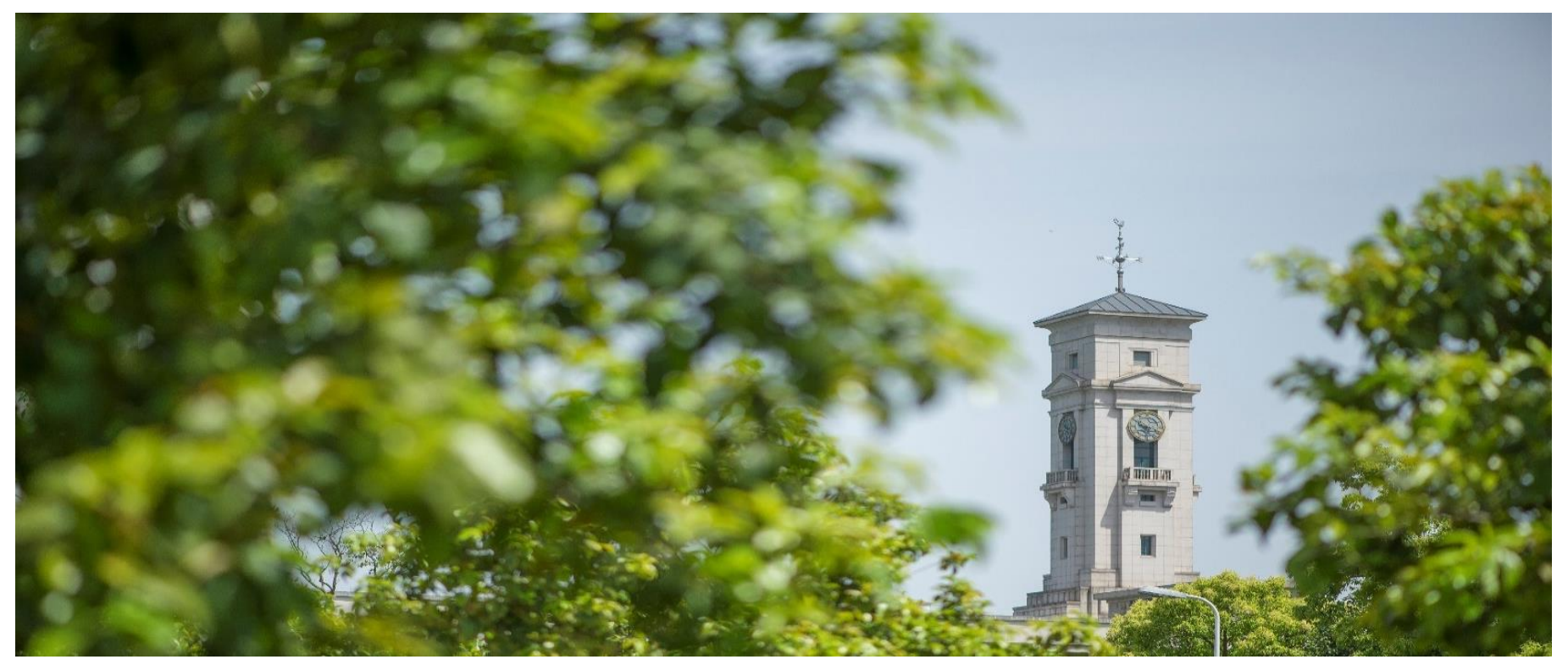


Faculty of Science and Engineering, University of Nottingham Ningbo China, 199 Taikang East Road, Ningbo, 315100, Zhejiang, China.

First published 2020

This work is made available under the terms of the Creative Commons Attribution 4.0 International License:

http://creativecommons.org/licenses/by/4.0

The work is licenced to the University of Nottingham Ningbo China under the Global University Publication Licence:

https://www.nottingham.edu.cn/en/library/documents/researchsupport/global-university-publications-licence-2.0.pdf 


\title{
Experimental analysis of a high temperature water heat pipe for thermal storage applications
}

\author{
Thomas C. Werner ${ }^{\mathrm{a}, \mathrm{b} *}$, Yuying Yan ${ }^{\mathrm{a}, \mathrm{c}}$, David Mullen $^{\mathrm{b}}$, Elvedin Halimic $^{\mathrm{b}}$ \\ aDepartment of Fluids and Thermal Engineering, University of Nottingham, Nottingham, UK \\ ${ }^{\mathrm{b}}$ Applications Engineering Department, Aavid Thermacore Europe Ltd., Ashington, UK \\ ${ }^{\mathrm{c}}$ Research Centre for Fluids and Thermal Engineering, University of Nottingham Ningbo China, Ningbo \\ 315100, China \\ Email of corresponding author: thomas.werner@nottingham.ac.uk
}

\begin{abstract}
Heat pipes spanning the $300^{\circ} \mathrm{C}$ to $500^{\circ} \mathrm{C}$ temperature range are still under research and development stage. Monel/water heat pipes have been previously explored as an option for operation up to $300^{\circ} \mathrm{C}$. Life tests of up to 30000 hours have shown good compatibility at $250^{\circ} \mathrm{C}$. The author explores the performance of a heat pipe using a different copper/nickel alloy with water as the working fluid at temperatures above $280^{\circ} \mathrm{C}$. The performance of these water heat pipes at the upper limit of their operational temperature range in the horizontal position is highlighted and compared against numerical calculations of the heat pipe boiling limit. The use of these heat pipes in the context of thermal storage applications is also briefly explored.
\end{abstract}

Key Words: Heat pipe, Thermal Management, Thermal Storage, Boiling Limit, Capillary Limit, Experimental Thermodynamics

\section{Introduction}

Heat pipes can be described as structures of very high thermal conductance. They are used as means to distribute and/or dissipate heat within a physical system and provide an excellent alternative to active cooling systems through their ability to conduct large heat fluxes from source to sink using solid and passive heat pipe structures. The distinct advantage of these is their light weight, reliability, minimal maintenance requirements and an extensive working life. Currently, they play a vital role in the heat transfer systems in a wide range of industries such as power electronics, automotive design, space craft design, consumption electronics and 
power generation [1-7]. Research and development into the technology has increased dramatically in the past two decades due to the increased need for heat management in these industries.

Conventionally, Copper/Water heat pipes function up to $250^{\circ} \mathrm{C}$, after which the copper structure becomes too weak to support the vapour pressure [8]. Previous tests by Sarraf et. al. [9] and Rosenfeld et. al. [8] have determined that Monel is a good substitute for copper at higher temperatures due to its increased strength. Monel/water heat pipes have been previously explored as an option for operation up to $300^{\circ} \mathrm{C}[8,10]$. Life tests performed by Rosenfeld et. al. [8] and Anderson et. al. [11] have shown great promise. The exploration of another CopperNickel alloy as the wall material is conducted and its performance at high temperatures is evaluated. Preliminary internal results show that the $\mathrm{Cu} / \mathrm{Ni}$-water heat pipes are fully functional up to $300^{\circ} \mathrm{C}$ within the predicted capillary and boiling limit ranges, however, further exploration into the capillary and boiling limit of these heat pipes and quantification of their performance at temperatures above $280^{\circ} \mathrm{C}$ is needed and is the main focus of this study.

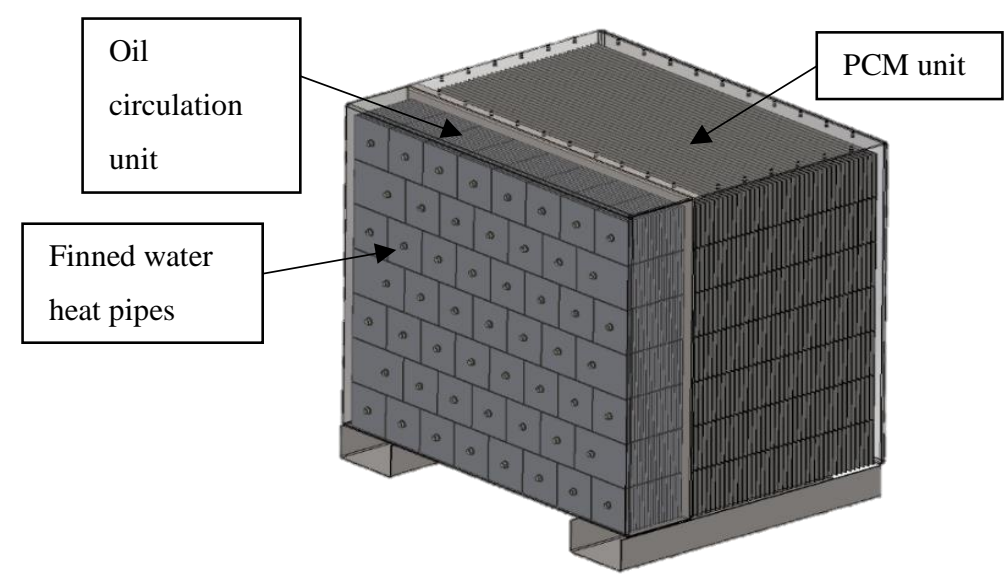

Figure 1. Innova Microsolar [1] PCM heat storage system using water heat pipes

The use of water heat pipes at these elevated temperatures stems from new emerging technologies requiring high performance heat transfer thermal storage particularly in the application of solar-thermal power plants. The heat pipe specification in this study follows the design requirements for a $4 \mathrm{~kW}$ thermal storage unit utilizing a Phase Change Material (PCM) to store surplus heat from a solar heated thermal oil used primarily for an organic Rankine Cycle (see Figure 1) as part of the Innova Microsolar project [1]. This application determined the main dimensional and performance requirements for the heat pipe. Each heat pipe is 
expected to carry a maximum of $150 \mathrm{~W}$ in the horizontal position at temperatures varying between $250-300^{\circ} \mathrm{C}$. For this study, the main point of interest lies in the upper end of the range $\left(280-300^{\circ}\right)$ as this is reaching the maximum limit of water functionality as a heat pipe fluid.

Various authors have previously explored the use of water heat pipes in a variety of applications requiring elevated temperature. Rosenfeld et. al. [7] looks at Titanium/Water heat pipes for spacecraft heat rejection systems. The operation required up to $1 \mathrm{~kW}$ of energy to be transported at $225^{\circ} \mathrm{C}$. The tests demonstrate the capability of high power delivery of water heat pipes with trapezoidal and rectangular sintered wicks. Life tests also demonstrate the longevity of the heat pipes at high temperatures. Anderson et. al. [11] demonstrates life testing on CP-Titanium and Monel K-500 heat pipes filled with water. All heat pies were tested at $277^{\circ} \mathrm{C}$ and contained screen wicks. The CP-Titanium heat pipes showed a small increase in temperature difference over time, whereas Monel heat pipes remained constant. At the time the paper was published, the heat pipes had undergone roughly $10000 \mathrm{~h}$ of testing.

To quantify the performance of the heat pipe, techniques used by Ghanbarpour et. al. [12] on screen mesh heat pipes containing nanofluids demonstrate the use of effective thermal conductivity and thermal resistance as quantitative measures of experimental results. Studies on the boiling limitations span a variety of studies as discussed in section 2.4. Some of the most comprehensive studies directed specifically towards heat pipe structures include work by Ferrell et. al. [13] and Ivanovkii et. al. [14]. In these studies, empirical formulae are derived from experimentation with meshed and porous surfaces.

This study intends to prove the functionality of new test facilities able to reach condenser temperatures of up to $350^{\circ} \mathrm{C}$. Water heat pipes were used to validate the rig as well as prove and quantify the functionality of the pipes for thermal storage applications. The facility intends to also have the capability of testing novel medium temperature heat pipe fluids in future. Life tests on the heat pipe developed for this study are being commissioned to prove their long term functionality. Reports on their progress will be done at the 10000h mark for direct comparison against tests by Anderson et. al. [11].

\section{Experimental and Numerical Methodology}

\subsection{Heat pipe specification}


Numerical modelling, as presented in section 2.4, was used to first asses the performance of the water heat pipe over its operating range and determine its suitability for the application. Figure 2 shows the full operating domain of the heat pipe with respect to operating angle and temperature. This gives an indication of the maximum axial power transmission over its entire operating range including various inclination angles. The final heat pipe design operates at a safety factor of 2 up to $300^{\circ} \mathrm{C}$ and utilises a mesh wick structure, all other details and dimensions can be found in Table 1 .

The heat pipe was designed and assembled at Aavid Thermacore Europe Ltd. following industry standard assembly procedures. An end cap and fill tube were welded at each end of $0.46 \mathrm{~m}$ long and $0.8 \mathrm{~mm}$ thick pipe once the mesh was placed inside. Helium leak checks were performed to test the weld joints and pull a 7E-10 mBar vacuum inside the pipe. Afterwards, the heat pipe was loaded with $6.5 \mathrm{cc}$ of DI water and tested for presence of non-condensable residual gasses. Once all procedures were successfully completed, the fill tube was crimped and welded shut. The heat pipe was then re-tested to ensure it still met the standard dT requirements.

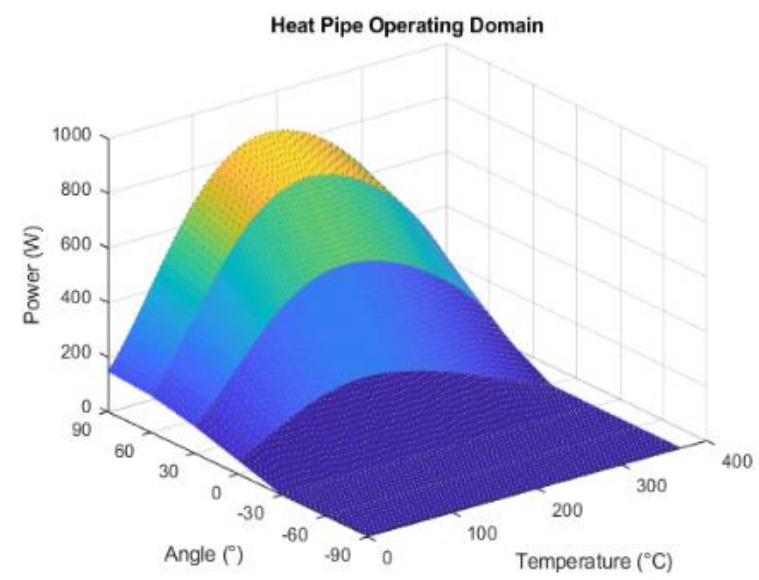

Figure 2. Water heat pipe operating domain
Table 1

Heat Pipe Dimensions.

\begin{tabular}{ll}
\hline Measurement & Value \\
\hline Heat Pipe Length $(\mathrm{m}):$ & 0.46 \\
Evaporator Length $(\mathrm{m}):$ & 0.1 \\
Condenser Length $(\mathrm{m}):$ & 0.15 \\
Adiabatic Length $(\mathrm{m}):$ & 0.21 \\
Effective Length $(\mathrm{m}):$ & 0.23 \\
Diameter ( mm): & 12 \\
Wall Thickness ( mm): & 0.8 \\
Wall Conductivity (W/mK): & 29 \\
Orientation: & Horizontal \\
Screen Conductivity (W/mK): & 50 \\
Minimum Operating Temperature (C): & 50 \\
Maximum Operating Temperature (C): & 300 \\
Max Operating Power in application (W): & 150 \\
\hline
\end{tabular}

\subsection{Experimental apparatus and procedure}

The experimental facilities consist of an oil circulator with programmable temperature control 
capable of operating up to $350^{\circ} \mathrm{C}$, a high temperature Coriolis flow meter, a pneumatic valve and Pico logger for thermocouple signal processing. Condenser and heater blocks were custom built to fit the heat pipe and the power supply could deliver a power of up to $1 \mathrm{~kW}$ to the heat pipe. See Figure 3 for the experimental setup of the equipment.

The circulator can deliver a flow rate of up to $0.0167 \mathrm{Kg} / \mathrm{s}$ and provides a temperature reading accuracy of $0.01^{\circ} \mathrm{C}$. Flow meter is capable of reading the flow rate, density and temperature of the oil at an accuracy of $0.0001 \mathrm{~kg} / \mathrm{s}, 0.1 \mathrm{~kg} / \mathrm{m} 3$ and $0.01^{\circ} \mathrm{C}$ respectively. K-type thermocouples were used for temperature measurement along the heat pipe and at the inlet and outlet of the condenser block with a post-calibrated accuracy of $0.1^{\circ} \mathrm{C}$. Two separate control systems were used, one to control the circulator flow and temperature and the other to control the pneumatic valve and take readings from the Pico logger and flow meter.

The general experimental procedure is as follows:

1. Set the pre-determined flow rate and circulator temperature (determined through preliminary testing and setup)

2. Begin temperature data recording

3. Set the power to $100 \mathrm{~W}$

4. Wait until steady state is reached (temperature variance of $<0.5^{\circ} \mathrm{C}$ over 30 minutes)

5. Stop temperature recording and save file

6. Begin new temperature recording

7. Increase power by $20 \mathrm{~W}$

8. Repeat steps 4 to 7 until obvious dry-out is reached or vapour temperature becomes $>$ $320^{\circ} \mathrm{C}$

As the main application concerns the PCM thermal storage unit, in which the heat pipes operate horizontally, the water filled $\mathrm{Cu} / \mathrm{Ni}$ heat pipes were tested only in the horizontal position. Not only does this demonstrate the limitations of a water filled heat pipe operating above $280^{\circ} \mathrm{C}$ but also this gives an empirical value to the conductivity and thermal resistance of the heat pipes which can be used in subsequent application simulations. 


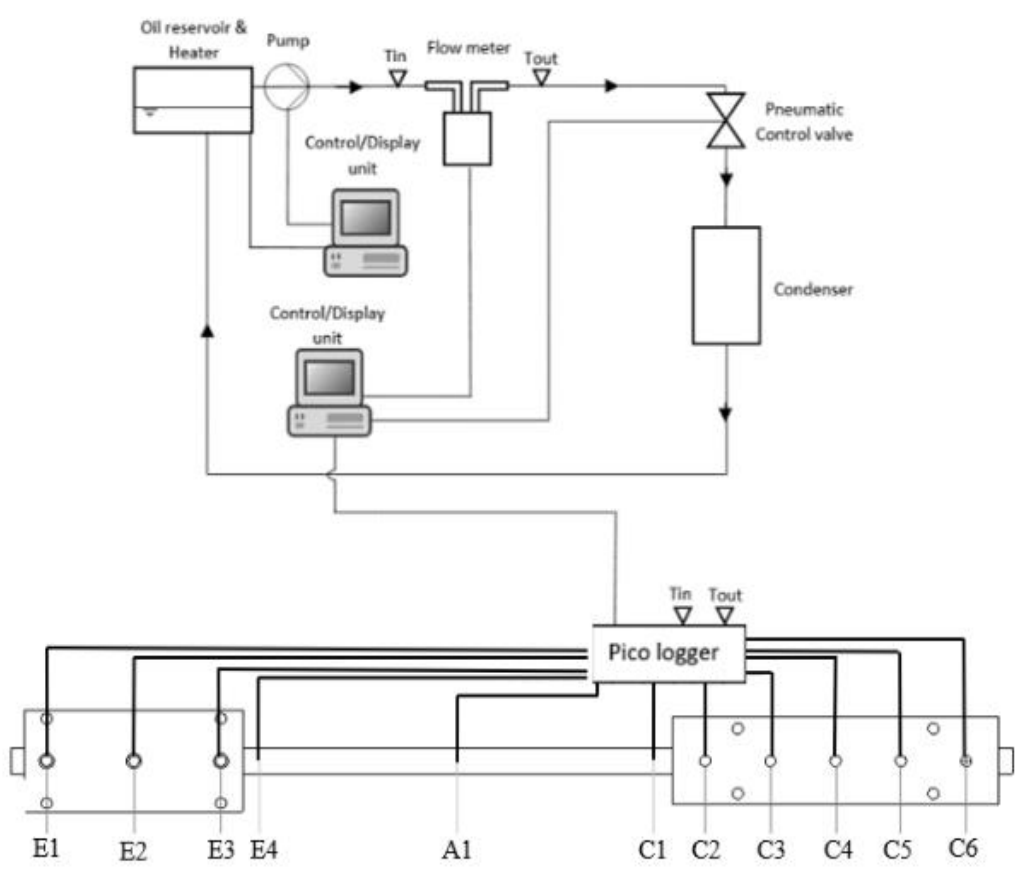

Figure 3. Experimental setup. Where prefixes ' $E$ ', 'A' and 'C' signify thermocouples located at the evaporator, adiabatic and condenser sections respectively.

\subsection{Data reduction}

During production testing, the main identifier for the heat pipe functionality is the temperature differential of the heat pipe extremities ( $\Delta T_{e 2 e}$, see Table 2$)$. This, however, does not give a complete picture of the heat pipe performance within a system as it does not serve as measure of the heat flux at the evaporator and condenser or provide any measure of the axial heat flux. Using the experimental equipment and procedure detailed in section 2.2, various heat pipe performance indicators were determined before testing which would provide a better understanding of the heat pipe behaviour. First, the various experimental measures of temperature difference was identified as seen in Table 2. Further determinants of the heat pipe performance are the thermal resistance $(R)$, the average temperature difference of the heater and condenser section $\left(\Delta T_{a v}\right)$ and the effective conductivity $\left(K_{e}\right)$ of the heat pipe. These are characterised through equations 1,2 and 3 respectively.

$$
\begin{gathered}
R=\frac{T_{e}-T_{c}}{Q} \\
\Delta T_{a v}=A v(E 1 \rightarrow E 4)-A v(C 1 \rightarrow C 6)
\end{gathered}
$$




$$
K_{e}=\frac{l_{\text {eff }}}{A_{c} R}
$$

All these qualities can act as an indicator to when a limitation point is reached. In this study, a quantitative analysis of these properties are reported from and experimental data to aid in any subsequent system modelling which would utilize these heat pipes. Additionally, a cross examination of each of these values is made in order to determine the limitation point of the heat pipe and show the behaviours of the heat pipe around the boiling limit.

Table 2

Various experimental temperature difference definitions. The ' $\mathrm{E}$ ' and ' $\mathrm{C}$ ' variables are temperature readings in the positions indicated in Figure 3.

\begin{tabular}{cl}
\hline Formula & Description \\
$d T_{e 2 e}=E 1-C 6$ & End to end heat pipe dT \\
$d T_{a v}=A v(E 1 \rightarrow E 4)-A v(C 1 \rightarrow C 6)$ & Average heat pipe dT \\
$d T_{a d i}=E 4-C 1$ & Adiabatic dT \\
$T_{e}=A v(E 1 \rightarrow E 3)$ & Average evaporator temperature \\
$T_{c}=A v(C 2 \rightarrow C 6)$ & Average condenser temperature \\
$d T_{R}=T e-T c$ & Thermal resistance dT \\
$T_{v a p}=A v\left(T_{e}, T_{c}\right)$ & Vapour temperature \\
$d T_{e}=T_{e}-T_{v a p}$ & Evaporator dT \\
$d T_{\max }=\operatorname{Max}(E 1 \rightarrow E 4)-\operatorname{Min}(C 1 \rightarrow C 6)$ & Maximum recorded temperature difference
\end{tabular}

\subsection{Numerical modelling}

The heat pipe numerical modelling uses selected empirical formulae to quantify each heat pipe limitation curve. The principal limitations which are of interest in this study are the capillary and boiling limits as these are the dominant limitations at the upper operating temperatures. The capillary limit is the point at which the sum of the liquid, vapour and gravitational pressure differentials become greater than the capillary pressure [15], this is demonstrated in Equation (4).

$$
\Delta P_{c, \max } \geq \Delta P_{l}+\Delta P_{v}+\Delta P_{g}
$$

From substituting the empirical correlations for each pressure value in Equation 4, this balance can be expressed as seen in Equation (5) [15].

$$
\frac{2 \sigma}{r_{e f f}} \geq \frac{\mu_{l} Q l_{e}}{\pi\left(r_{w}^{2}-r_{v}^{2}\right) \varepsilon r_{c}^{2} \rho_{l} h_{f g}}+\frac{8 \mu_{v} Q}{\pi \rho_{v} R_{v}^{4} h_{f g}}+\rho_{l} g\left(l_{e}+l_{a}\right) \sin \theta
$$


The boiling limit has been widely studied for a variety of surface conditions and wick types [18], however, it remains a notoriously difficult limit to predict with certainty due to the 'random' nature of the boiling phenomena and the number of factors which can affect it (porosity, permeability, effective thermal conductivity, capillary potential, etc.). Various empirical correlations have been defined to describe the boiling phenomenon within different types of wick structures, surface conditions and geometries. In general it was found that boiling a liquid from a porous surface required much lower wall superheating due to the excess of nucleate boiling sites [19]. A study by Marto et. al. [19] analysed this phenomenon by observing pool boiling from various metallic porous surfaces. Experiments conducted by Ivanovskii et. al. [14] using sodium compound wicked heat pipes showed that the heat fluxes reached at the evaporator wall were three times higher than the critical heat fluxes under pool boiling conditions. Several authors have proposed relationships to predict the critical heat flux under approximate conditions found inside a heat pipe [15], a summary of the principal correlations considered for this study is presented in Table 3.

Table 3 Empirical boiling correlations

\begin{tabular}{|c|c|}
\hline Author & Correlation \\
\hline $\begin{array}{l}\text { Rohsenow and Griffith } \\
\text { [16] }\end{array}$ & $q_{c r}=0.012 L \rho_{v}\left(\frac{\rho_{l}-\rho_{v}}{\rho_{v}}\right)^{0.6}$ \\
\hline $\begin{array}{l}\text { Caswell and Balzhieser } \\
\text { [17] }\end{array}$ & $q_{c r}=1.02 \times 10^{-6} \frac{L^{2} \rho_{v} k_{l}}{c_{p}^{\gamma}}\left(\frac{\rho_{l}-\rho_{v}}{\rho_{v}}\right)^{0.6} \operatorname{Pr}^{0.71}$ \\
\hline Ferrell et. al. [13] & $q_{c r}=\frac{g\left(h_{c o} \rho_{l}\left(\frac{\sigma_{l}}{\sigma_{l o}}\right)-\rho_{l} l \sin \theta\right)}{\frac{l_{e} \mu_{l}}{h_{f g} \rho_{l} k d}\left(\frac{l_{e}}{2}+l_{a}\right)}$ \\
\hline Ferrell et. al. [13] & $q_{c r}=\frac{g\left(h_{c o} \rho_{l}\left(\frac{\sigma_{l}}{\sigma_{l o}}\right)-\rho_{l} l \sin \theta\left(1+\alpha_{t} \Delta T\right)\right)}{\frac{l_{e} \mu_{l}}{h_{f g} \rho_{l} k d\left(1+\alpha_{t} \Delta T\right)}\left(\frac{l_{e}}{2}+l_{a}\right)}$ \\
\hline $\begin{array}{l}\text { Ivanovskii et al } \\
\text { [14] }\end{array}$ & $q_{c r}^{\cdot}=\frac{4 \pi l_{e} \lambda_{e} T_{v} \sigma_{l}}{h_{f g} \rho_{v} \ln \frac{r_{i}}{r_{v}}}\left(\frac{1}{r_{n}}-\frac{1}{r_{e f f}}\right)$ \\
\hline
\end{tabular}

The boiling limit chosen for this study is that by Ivanovskii et. al. [14]. The equation is a derivation of the critical heat flux for an equivalent planar mesh surface is commonly used in the heat pipe field by numerous authors including Chi [20] and Faghri [21]. The re-arrangement of the equation to determine the maximum transport power is presented in Equation 6. 


$$
Q_{b}=\frac{2 \pi l_{e} k_{e} T_{v}}{h_{f g} \rho_{v} \ln \left(\frac{r_{i}}{r_{v}}\right)}\left(\frac{2 \sigma}{r_{n}}-P_{c, \text { max }}\right)
$$

Where ' $r_{n}$ ' indicates the maximum nucleation radius (i.e. the maximum bubble radius which can be released from the wick structure pores). This equation is a representation of the heat transfer rate required to maintain equilibrium vapour bubbles of radius ' $r_{b}$ ' within the wick. Depending on surface conditions and presence of dissolved gas, the nucleation radius has a finite value, ' $r_{n}$ ', to which bubbles will begin to grow within the wick structure and form film boiling conditions. The nucleation radius largely relies on empirical data to be determined and have a large variance from wick to wick. One estimation method would be to use the pore size of the wick as the maximum nucleation value, depending on the homogeneity of the wick, however, this could present a large error. As mesh wick is used in this study, the porosity can indeed have a lot of variance which is reflected in the attained results. The approach in this case was to match a range of ' $r_{n}$ ' values to the acquired data. In this case, the average value of the range can be used for future predictions using the designated wick structure or a maximum and minimum range value can be used depending on the application.

These two limitations form the principal power limitation modelling of the heat pipe, giving origin to the heat pipe power output curves seen in Figure 2. Other limitation such as the sonic, entrainment and viscous limit were also modelled, these showed to have no effect on the operation of the heat pipe at high temperatures. This is ascertained by Reay and Kew [15] who demonstrate that these equations are relevant only at start-up and low temperature conditions due to the low pressure gradients which lead to high vapour velocities.

\section{Results and Discussion}

The first point of discussion is in the measure of temperature difference of the heat pipe and how these measurements can be used and interpreted. In order to calculate the theoretical temperature difference, a thermal resistance network is usually employed where the sum of the thermal resistances of the wall material and wick gives the total thermal resistance across the heat pipe. In an application, however, it is unlikely that these will be the only thermal resistances present between the heat sources and sink. Other factors, such as contact resistance, radiation and parasitic heating/cooling all have an effect on the measurement of the heat pipe 
wall temperature. This is demonstrated in the variety of temperature differences that can be extracted from the data as seen in Table 2 . The main measurements are 'end to end' temperature difference, average temperature difference, adiabatic temperature difference and maximum temperature difference. These are all valid quantities which can be use in the thermal resistance and equivalent conductivity calculations. It is important to consider which one to use in any subsequent calculations as these will each give a different interpretation of the functionality of the heat pipe. For this study, the average temperature difference was chosen as the preferable option as this uses averaged values (which increases the statistical accuracy) and gives a better representation of the average surface temperatures of the evaporator and condenser sections taking into account any potential temperature gradients within the heater and condenser blocks. It also gives a more representative value towards the final application which will use a similar measure to determine the effectiveness of the heat pipe and system as a whole.

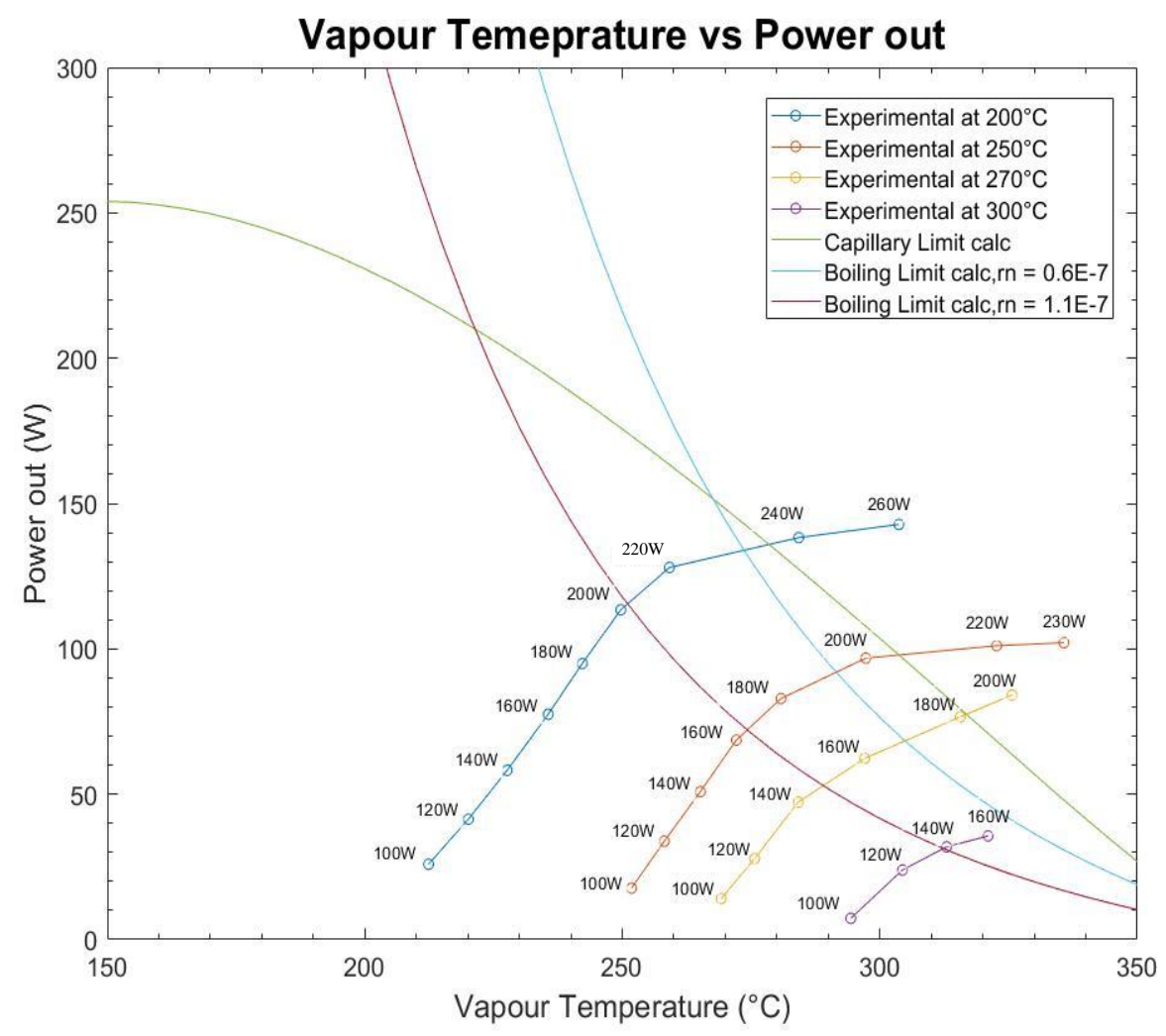

Figure 4 Experimental and numerical power prediction results. Values next to experimental data points indicate the input power for the steady state condition. The points within the calculated boiling limit curves are proposed as the 'transition' zone. 
In order to determine where the power limit lies in the heat pipe at vapour temperatures approaching and above $280^{\circ} \mathrm{C}$, the test requires the heat pipe to slowly approach the operating limit by increasing the power input in small steps. To regulate the vapour temperature and alter the point at which the limitation is reached, the condenser oil loop was set to four different temperatures; $200,250,270$ and $300^{\circ} \mathrm{C}$. Various flow rates were initially explored to determine the highest possible heat extraction without compromising the accuracy of the power output readings. Once this was determined, the heat input was increased in steps of $20 \mathrm{~W}$, stating form $100 \mathrm{~W}$, until dry-out was reached at each condenser temperature. The main objectives of the test is to measure the change in performance at and beyond the heat transportation limit, identify the indictors (i.e. heat pipe temperature difference, vapour temperature or thermal resistance) that could best describe the point at which the capillary or boiling limits are reached experimentally and, from this, determine the range of maximum nucleation radius values, ' $r_{n}$ ', which would best describe the heat pipe boiling limit numerically. Each experimental data point in Figure 4 indicates the steady state vapour temperature and power outputs achieved for the each input power step at a constant condenser temperature. The first impression taken from the experimental data presented in Figure 4 is that there appears to be a 'transition zone' in which the heat pipe can still effectively transport heat, but there is a clear break form the linear trend line of increasing power input. After this point is reached, a further power increase results

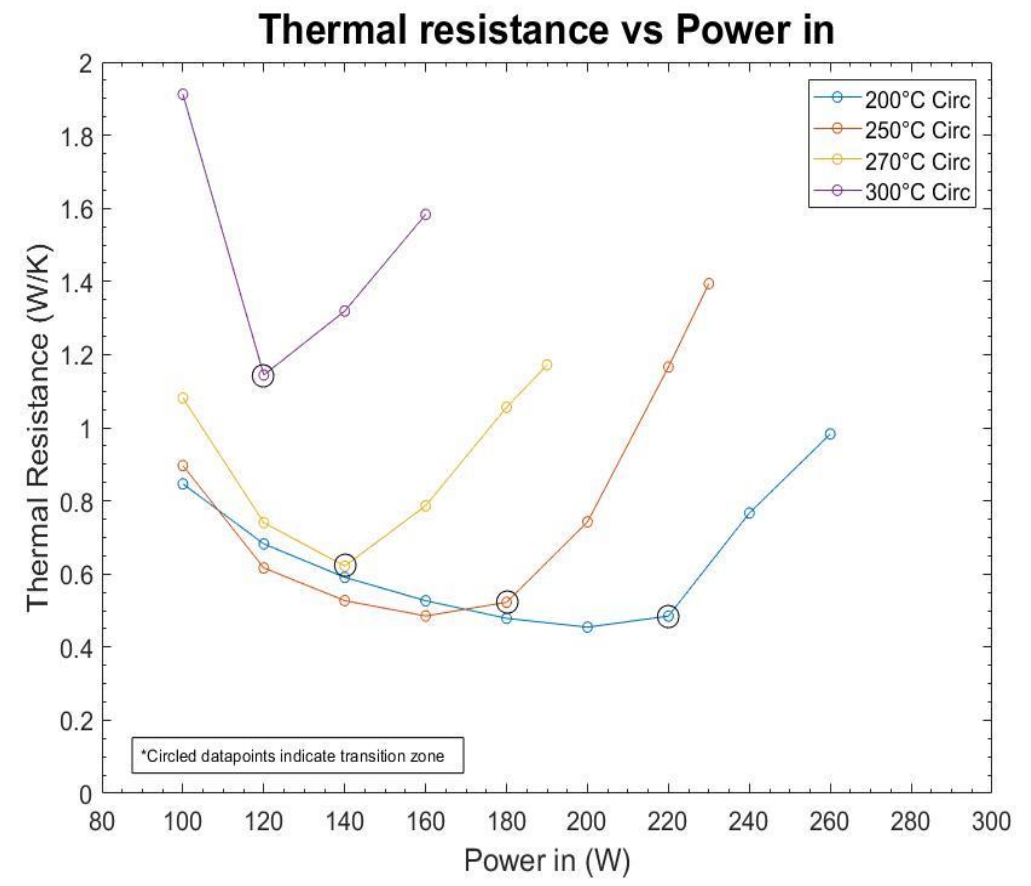

Figure 5 Thermal resistance at each experimental steady state against input power. Circled values indicate an alternative indication for the 'transition' zone. Here the transition point for $270^{\circ} \mathrm{C}$ and $300^{\circ} \mathrm{C}$ circulator temperature differ from those indicated in Figure 4. 
only in the increase of the vapour temperature with a plateau in output power - a clear indication that wick dry-out has occurred and the boiling limit has been reached.

At lower condenser temperatures of 200 and $250^{\circ} \mathrm{C}$, there is a clear change in gradient indicating a heat transport limitation has been reached. The numerical model for the boiling limit was calculated for a range of maximum nucleation radii from 1.1E-7 and 0.6E-7. The boiling limit curves showed trend lines correlating with the start and end of the proposed 'transition zone'. At higher condenser temperatures of 270 and $300^{\circ} \mathrm{C}$, there becomes a less defined limitation point with a smoother gradient change. This may indicate that the heat pipe is already operating at or near its operating limit but is still able to transfer heat somewhat effectively. Another indicator for the transition point in these cases are the thermal resistance as shown in Figure 5. It is observed that in the case of the 270 and $300^{\circ} \mathrm{C}$ condenser temperatures, there is a clear change in thermal resistance which could serve as an alternative indicator for the limitation point where the 'transition zone' is less defined though the vapour temperature data alone. These, however, differ from the points identified in Figure 4 as they occur at lower input powers of $140 \mathrm{~W}$ and $120 \mathrm{~W}$ for circulator temperatures of $270^{\circ} \mathrm{C}$ and $300^{\circ} \mathrm{C}$ respectively. This indicates that the boiling point may be occurring at lower powers than predicted for higher vapour temperatures and it may be advisable to use the lower end of the boiling limit transition zone in this case (i.e. $\mathrm{rn}=1.1 \mathrm{E}-7$ ).

\section{Table 4}

Heat pipe performance at transition point indicated in Figure 4

\begin{tabular}{|c|c|c|c|c|c|c|}
\hline $\begin{array}{l}\text { Circulator } \\
\text { temperature } \\
\left({ }^{\circ} \mathrm{C}\right)\end{array}$ & $\begin{array}{l}\text { Vapour } \\
\text { Temperature } \\
\text { at transition } \\
\text { point }\left({ }^{\circ} \mathrm{C}\right)\end{array}$ & $\begin{array}{l}\text { Thermal } \\
\text { resistance at } \\
\text { transition } \\
\text { point }(K / W)\end{array}$ & $\begin{array}{l}\text { Power } \\
\text { output at } \\
\text { transition } \\
\text { point }(W)\end{array}$ & $\begin{array}{l}\text { dTav at } \\
\text { transition } \\
\text { point }\left({ }^{\circ} \mathrm{C}\right)\end{array}$ & $\begin{array}{l}\text { dTadi at } \\
\text { transition } \\
\text { point }\left({ }^{\circ} \mathrm{C}\right)\end{array}$ & $\begin{array}{l}\text { Effective thermal } \\
\text { conductivity at } \\
\text { transition point } \\
(\mathrm{W} / \mathrm{mK})\end{array}$ \\
\hline 200 & 259.1 & 0.43 & 144 & 62 & 13.5 & 6668.5 \\
\hline 250 & 280.8 & 0.52 & 82.9 & 43.3 & 9.8 & 5499 \\
\hline 270 & 297 & 0.79 & 62.3 & 49 & 9.1 & 3653.6 \\
\hline 300 & 321 & 1.58 & 35.6 & 56.4 & 10 & 1815 \\
\hline
\end{tabular}

Table 4 presents the results of the steady state tests that fall within the 'transition zone' in Figure 4. From this data, it can be observed that there is a large increase in the thermal resistance as vapour temperature increases, particularly in the 270 to $300^{\circ} \mathrm{C}$ condenser temperature values. The effect of increasing the condenser temperature in step of 50, 20 and $30^{\circ} \mathrm{C}$ appeared to have relatively uniformly increased the boiling limit vapour temperature by 
roughly $20^{\circ} \mathrm{C}$ at each step, whereas the power output at the transition point tended to decrease in near equivalent steps to the condenser temperature step magnitudes at $61.1,20.6$ and $26.7 \mathrm{~W}$ power difference respectively. Theoretically, the effective thermal conductivity should decrease as the vapour temperature increases as the liquid thermal conductivity tends to decrease which results in an overall increase of the wick thermal resistance. This remained true for the effective conductivity trend seen in the experimental results. It is important to note that if the heat pipe were to be operated well within the operating limitation, the effective conductivity would remain the same, making the use of this value a powerful tool in heat pipe modelling.

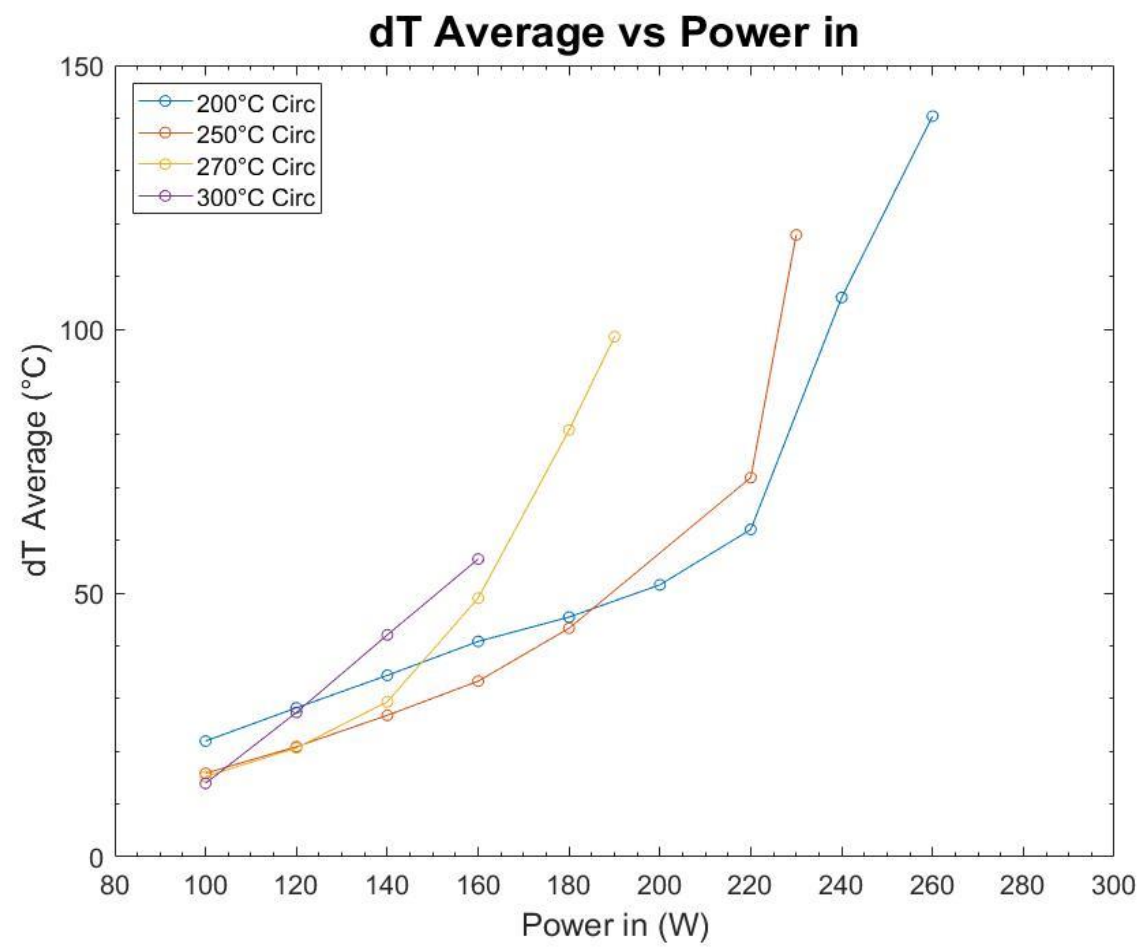

Figure 6 Average temperature difference (see Table 2) against the input power for experimental steady state results

Figure 6 shows the trend of average temperature difference values for each experiment as the power to the evaporator end is increased. It is expected that the temperature difference at each power input would be the same across all circulator temperatures (as long as it's within the limitation curve). It can be observed that the temperature difference values remain within a consistent range until the transition point is achieved. At circulator temperatures of 250 and $270^{\circ} \mathrm{C}$, the temperature difference is consistent for power inputs of 100 to $140 \mathrm{~W}$, remaining within a $10 \%$ range. For a circulator temperature of $200^{\circ} \mathrm{C}$, the values still follow the general trend, however, they appear to incur a systematic error throwing them out of range from the 
250 and $270^{\circ} \mathrm{C}$ values. This may have been the consequence of the presence of potential systematic error in the $200^{\circ} \mathrm{C}$ condenser tests cause by an unexpected change in ambient conditions and/or change in the insulation uniformity and packing density, which are a very difficult factor to monitor and keep consistent from test to test.

\section{Conclusions}

The study successfully lays out an experimental method for identifying the power limit (in this case the boiling limit) at high vapour temperatures of water using analyses on the power output and thermal resistance. The use of water filled copper alloy heat pipes for use in thermal storage applications at temperatures above $280^{\circ} \mathrm{C}$ has been demonstrated to be somewhat effective should the condenser temperature be kept below $300^{\circ} \mathrm{C}$. When the condenser is operating at this temperature, particularly in the horizontal orientation, the pipe is susceptible to rapid decline in thermal conductivity due to reaching the boiling limit at a relatively low power input. Operation in the identified 'transition zone', however, is still able to effectively transport heat without too much detriment.

From this analysis it is clear that there is a change in behaviour of the heat pipe beyond a certain vapour temperature corresponding to the boiling limit equation with a nucleation radius between $0.6 \mathrm{E}-7$ and $1.1 \mathrm{E}-7$. As the vapour temperature increases, the transition point becomes less pronounced. It has been shown in these cases that the thermal resistance values could give an alternative indication of when the boiling limit occurs. Results showing the performance of the heat pipe at each experimental boiling limit point is presented with the calculated equivalent thermal conductivity. The main conclusions of the study are as follows:

- Experimental results show that the boiling limit could lie between maximum nucleation radii of 1.1E-7 and 0.6E-7 in the proposed boiling equation by Chi [20] and Faghri [21]

- Thermal resistance values can give an alternative indicator of reaching the boiling limit where the transition zone is less pronounced. This may differ from that defined by the capillary limit.

- Equivalent thermal conductivity values have been calculated for a copper alloy/water heat pipe operating at the boiling limit above $280^{\circ} \mathrm{C}$

- At vapour temperature above $250^{\circ} \mathrm{C}$ the thermal resistance substantially increases, but 
effective heat transfer can still occur up to the output powers presented in Table 4.

\section{Acknowledgments}

This project was made possible through the support of the EPSRC in funding the doctoral project entitled "Medium temperature heat pipes: fluid analysis, testing and development", the European Commission funding through the Innova Microsolar project (project code 723596), additional funding from Aavid Thermacore Europe Ltd. (under Boyd Corporation) and European H2020-MSCA-RISE ThermaSMART project (project code 778104).

The authors would like to thank all participating staff at Aavid Thermacore Europe Ltd., in particular Steven Cochran and Kevin Lynn for supporting this project. Also the Innova Microsolar team at Northumbria University for their valuable insights.

\section{Nomenclature}

$\begin{array}{ll}\mathrm{A}_{\mathrm{c}} & \text { Condenser surface area, } \mathrm{m}^{2} \\ \varepsilon & \text { Porosity, } \% \\ \mathrm{~g} & \text { Gravitational acceleration, } \mathrm{m} / \mathrm{s}^{2} \\ \mathrm{~h}_{\mathrm{fg}} & \text { Latent heat capacity, } \mathrm{J} / \mathrm{Kg} \\ \mathrm{k} & \text { Conductivity, W/mK } \\ \mathrm{k}_{\mathrm{e}} & \text { Effective conductivity, W/mK } \\ \mathrm{l}_{\mathrm{a}} & \text { Adiabatic length, } \mathrm{m} \\ \mathrm{l}_{\mathrm{e}} & \text { Evaporator length, } \mathrm{m} \\ \mathrm{l}_{\mathrm{eff}} & \text { Effective length, } \mathrm{m} \\ \mathrm{l}_{\mathrm{i}} & \text { Heat pipe length, } \mathrm{m} \\ \mathrm{P}_{\mathrm{c}, \mathrm{max}} & \text { Maximum capillary pressure, Pa } \\ \mathrm{P}_{\mathrm{g}} & \text { Gravitational pressure, } \mathrm{Pa} \\ \mathrm{P}_{\mathrm{l}} & \text { Liquid pressure, } \mathrm{Pa} \\ \mathrm{P}_{\mathrm{v}} & \text { Vapour pressure, } \mathrm{Pa} \\ \mathrm{Q} & \text { Heat, W } \\ \mathrm{Q}_{\mathrm{b}} & \text { Boiling limit, W } \\ \mathrm{Q}_{\mathrm{e}} & \text { Max evaporator power, W }\end{array}$




$\begin{array}{ll}q_{c r}^{\cdot} & \text { Critical heat flux, } \mathrm{W} / \mathrm{m}^{2} \\ \mathrm{R} & \text { Thermal resistance, } \mathrm{mK} / \mathrm{W} \\ \mathrm{r}_{\mathrm{c}} & \text { Capillary radius, } \mathrm{m} \\ \mathrm{r}_{\mathrm{e}} & \text { Effective radius, } \mathrm{m} \\ \mathrm{r}_{\mathrm{i}} & \text { Internal radius, } \mathrm{m} \\ \mathrm{r}_{\mathrm{v}} & \text { Vapour space radius, } \mathrm{m} \\ \mathrm{r}_{\mathrm{n}} & \text { Maximum nucleation radius, } \mathrm{m} \\ \mathrm{r}_{\mathrm{w}} & \text { Outer wick radius, } \mathrm{m} \\ \mathrm{r}_{\mathrm{v}} & \text { Vapour radius, } \mathrm{m} \\ \mathrm{T}_{\mathrm{av}} & \text { Average temperature },{ }^{\circ} \mathrm{C} \\ \mathrm{T}_{\mathrm{c}} & \text { Condenser temperature },{ }^{\circ} \mathrm{C} \\ \mathrm{T}_{\mathrm{e}} & \text { Evaporator temperature, }{ }^{\circ} \mathrm{C} \\ \mathrm{T}_{\mathrm{v}} & \text { Vapour temperature, }{ }^{\circ} \mathrm{C} \\ \theta & \text { Angle } \\ \mu l & \text { Liquid viscosity, } \mathrm{Kg} / \mathrm{ms} \\ \mu \mathrm{v} & \text { Vapour viscosity, } \mathrm{Kg} / \mathrm{ms} \\ \rho l & \text { Liquid density, } \mathrm{Kg} / \mathrm{m}^{2} \\ \rho \mathrm{v} & \text { Vapour density, } \mathrm{Kg} / \mathrm{m}^{2} \\ \sigma & \text { Surface tension, } \mathrm{N} / \mathrm{m} \\ & \end{array}$

\section{Conflicts of interest statement}

There are no conflicts of interest.

\section{References}

[1] "Innova Microsolar Project." http://innova-microsolar.eu/ (accessed April 29, 2019).

[2] J. H. Rosenfeld and J. E. Lindemuth, "Sulfur Heat Pipes for 600 K Space Heat Rejection Systems," NASA, NASA L ERC, 1992, vol. Contract No. NAS3-26324.

[3] F. Aghbalou, A. Touzani, M. Mada, M. Charia, and A. Bernatchou, "A parabolic solar collector heat-pipe heat exchanger reactor assembly for cyclohexane's dehydrogenation: A simuation study," Renewable Energy, vol. 14, no. 1, pp. 61-67, 1998, doi: http://dx.doi.org/10.1016/S0960-1481(98)00048-2.

[4] L. Hongpeng and L. Weiqiang, "Thermal-structural analysis of the platelet heat-pipecooled leading edge of hypersonic vehicle," Acta Astronautica, vol. 127, pp. 13-19, 2016/11// 2016, doi: http://dx.doi.org/10.1016/j.actaastro.2016.05.014.

[5] M. Groll, "Heat pipe research and development in western Europe," Heat Recovery 
Systems and CHP, vol. 9, no. 1, pp. 19-66, 1989, doi: http://dx.doi.org/10.1016/08904332(89)90139-7.

[6] W. Zhang, C. Wang, R. Chen, W. Tian, S. Qiu, and G. H. Su, "Preliminary design and thermal analysis of a liquid metal heat pipe radiator for TOPAZ-II power system," Annals of Nuclear Energy, vol. 97, pp. 208-220, 2016, doi: http://dx.doi.org/10.1016/j.anucene.2016.07.007.

[7] J. H. Rosenfeld and N. J. Gernert, "Advances in High Temperature Titanium-Water Heat Pipe Technology," ed. Thermacore, Inc: Thermacore, Inc 2010.

[8] J. H. Rosenfeld, "Life test results for water heat pipes operating at $200^{\circ} \mathrm{C}$ to $300^{\circ} \mathrm{C}$," ed, 2008.

[9] D. B. Sarraf and W. G. Anderson, "High-Temperature Water Heat Pipes," ed, 2006.

[10] J. H. Rosenfeld, B. L. Drolen, C. Y. Lu, and M. S. El-Genk, "Design, Fabrication, and Testing of High Capacity High-Temperature Monel/Water Heat Pipes," (in en), research-article 2006-02-01 2006, doi: 1.2169187.

[11] W. G. Anderson, P. M. Dussinger, and D. Sarraf, "High temeprature water heat pipe life tests," in AIP Conference Proceedings, 2006: American Institute of Physics.

[12] M. Ghanbarpour, N. Nikkam, R. Khodabandeh, M. S. Toprak, and M. Muhammed, "Thermal performance of screen mesh heat pipe with A12O3 nanofluid," Experimental Thermal and Fluid Science, 2015.

[13] J. Ferrell, E. Alexander, and W. Piver, "Vaporization heat transfer in heat pipe wick materials," in 7th Thermophysics Conference, (Fluid Dynamics and Co-located Conferences: American Institute of Aeronautics and Astronautics, 1972.

[14] M. N. Ivanovskii, V. P. Sorokin, and I. V. Yagodkin, "Physical Principles of Heat Pipes," (in Turn on SafeSearch), Oxford Press Claredon, p. 130, 1982.

[15] D. Reay and P. Kew, Heat Pipes: Theory, Design and Applications, 6 ed. 2006.

[16] W. M. Rosenhow and P. Griffith, "Correlation of maximum heat flux data for boiling of saturated liquids," presented at the A.L.C.E. Heat Transfer Symposium, 1955.

[17] B. F. Casswell and R. E. Balzheiser, "The critical heat flux for boiling metal systems," presented at the Chemical Engineering Progress Symposium Series of Heat Tranfer, Los Angeles, 1966, 64.

[18] H. Smirnov, Transport phenomena in capillary-porous structures and heat pipes. CRC Press Taylor \& Francis Group, 2010.

[19] P. J. Marto and V. J. Lepere, "Pool Boiling Heat Transfer From Enhanced Surfaces to Dielectric Fluids," Journal of Heat Transfer, vol. 104, no. 2, pp. 292-299, 1982, doi: 10.1115/1.3245086.

[20] S. W. Chi, Heat pipe theory and practice. Hemisphere Pub. Corp, 1976.

[21] A. Faghri, Heat pipe science and technology. Washington, DC: Taylor \& Francis (in English), 1995. 